\title{
Social Safeguards in REDD+: A Review of Existing Initiatives and Challenges
}

\author{
Chandra Shekhar Silori $*$, Simone Frick*, Harisharan Luintel $* *$ and Bishnu Hari Poudyal $* * * *$ \\ *RECOFTC - The Center for People and Forests, Bangkok \\ **The School of Environment, Portland State University, USA \\ $* * *$ Grassroots Capacity Building for REDD + in Asia, RECOFTC, Nepal \\ Corresponding author: chandra.silori@recoftc.org
}

\begin{abstract}
Reducing emissions from deforestation and forest degradation, as well as conservation and enhancement of forest carbon stocks and promoting sustainable management of forests in developing countries (REDD+) has been proposed as an effective mechanism to mitigate the impacts of climate change. However, in view of the significant dependence of the local communities, indigenous peoples, women and other marginalized groups on the forest resources for their livelihoods and other daily needs, a number of apprehensions have been raised, citing the potential risk associated with the faulty design and weak implementation of the REDD + mechanism. In this context, a number of international initiatives have been proposing different sets of social and environmental safeguards, which can prevent potential social and/or environmental damage or harm to such forest-dependent communities and increase benefits for them in an equitable manner. By presenting brief overviews of various international level social and environmental safeguards, the authors argue that the initiatives taken so far provide a solid basis for formulating them at national level despite several challenges. There is a need to customize and harmonize the safeguard measures proposed so far with the national level initiatives related to forest/land rights, forest governance, benefits sharing, and so on. Ensuring effective and meaningful participation of local communities and civil society has been identified as challenging prerequisite to address genuine concerns of forest managing communities while developing, implementing and monitoring safeguard provisions. Similarly, allowing utmost important factor - flexibility - in the interpretation and implementation of safeguard provisions at the national and local contexts has to be recognized and managed properly.
\end{abstract}

Key Words: REDD + safeguards, REDD + social and environmental standards, SFM principles and criteria, free, prior and informed consent, women's carbon standard, MRV of REDD + safeguards

\section{INTRODUCTION}

It is now widely acknowledged that forests play an important role in mitigating the impacts of, and adapting to, climate change. Following the last couple of Conferences of Parties (COP) to the United Nations Framework Convention on Climate Change (UNFCCC), there has been a rapid proliferation of initiatives at international and national level that are aimed at reducing emissions from deforestation and forest degradation, as well as conservation and enhancement of forest carbon stocks and promoting sustainable management of forests, in developing countries, collectively known as REDD+. While REDD+ has the potential to deliver significant social and environmental cobenefits, many have also highlighted the serious risks (Murphy 2011), particularly for indigenous peoples, local communities, women and other marginalized communities, who depend significantly on the forests for their livelihoods and other daily needs. One potential way to address such risks is to have a set of social and environmental safeguards measures in place, which can prevent social and/or environmental 
damage or harm to such forest-dependent communities and increase benefits for them in an equitable manner.

During the COP15 held in Copenhagen in December 2009, a consensus was reached that a number of safeguards should be supported and promoted at both global and national level while undertaking REDD+ actions (UNFCCC 2009). This consensus was later developed into an agreement during the sixteenth session of the UNFCCC, i.e. COP 16 at Cancun and was considered as one of the most important breakthroughs in the climate change negotiations (Kant et al. 2011).

The social and environmental safeguards, as stipulated in Annex 1 of the Cancun Agreement
(UNFCCC 2011) (see Box 1), emphasize implementing REDD+ activities in accordance with the guidance provided by the COPs and cover a range of issues. These include conservation of natural forests and biological diversity, establishment of transparent and effective national forest governance structures, respect for the knowledge and rights of indigenous peoples and local communities, and their full and effective participation in the designing and implementation of REDD + . The agreement also stipulates that REDD+ actions need to be consistent with existing policies of the conservation of natural forests and biological diversity and serve to improve ecosystem services and enhance other social and environmental benefits (Kant et al. 2011).

\section{Box 1: United Nations Framework Convention on Climate Change (UNFCCC) safeguards articulated in the Cancun Agreement}

1. Actions complement or are consistent with the objectives of national forest programmes and relevant international conventions and agreements,

2. Transparent and effective national forest governance structures, taking into account national legislation and sovereignty,

3. Respect for knowledge and rights of indigenous people and local communities, by taking into account relevant international obligations, national circumstances and laws, and noting that the United Nations General Assembly has adopted the UN Declaration on the Rights of Indigenous Peoples,

4. Full and effective participation of relevant stakeholders, in particular indigenous people and local communities, in the actions referred to in paragraphs 70 and 72 of this decision,

5. Actions are consistent with the conservation of natural forests and biological diversity, ensuring that actions referred to in paragraph 70 of this decision are not used for the conversion of natural forests, but are instead used to incentivize the protection and conservation of natural forests and their ecosystem services, and to enhance other social benefits,

6. Actions to address the risk of reversals,

7. Actions to reduce the displacement of emissions.

Source: UNFCCC 2011

Following the Cancun Agreement, there have been a number of initiatives at global level to develop social and environmental safeguards by various multilateral and bilateral agencies, with a range of overlaps between them. This review provides an overview of some of the most discussed REDD+ safeguards, particularly the social safeguards, and initiatives to develop 
provisions and their integration at national level, and challenges with respect to the implementation, monitoring, reporting and verification of these safeguards at national level. Furthermore, the article also shares practical experiences related to addressing some of the key elements of social safeguards through training and capacity-building activities at grass roots level in four countries, viz. Lao PDR, Indonesia, Nepal and Vietnam. In these countries, RECOFTC - The Center for People and Forests has been implementing Grassroots Capacity Building program for REDD+, which is funded by the Norwegian Agency for Development Cooperation (NORAD). This project is being implemented since 2009, and following a cascade approach of training and capacity building at national, sub-national and grassroots level, the project has imparted training in the basic concepts of climate change, role of forests in climate change and REDD+, and the potential roles and responsibilities of grassroots stakeholders in REDD+ programme in the project countries (RECOFTC 2011; RECOFTC 2012). With respect to strengthening the understanding of grassroots stakeholders on social safeguards of REDD+, the project has also focused strongly on organizing training and capacity-building activities on gender mainstreaming and on Free, Prior and Informed Consent (FPIC) in REDD+. In this article, experiences from organizing such training programmes are also included as part of experience sharing.

\section{AN OVERVIEW OF REDD+ SAFEGUARDS}

The COP in Cancun laid a sound foundation on which a more comprehensive structure for REDD+ could be built in the future. Subsequent to the Cancun Agreement, a number of multilateral and bilateral initiatives have responded to develop sets of provisions for promoting social and environmental safeguards of REDD + . Some of them have also taken initiatives to integrate safeguards within national REDD+ frameworks. Following is a brief review of current initiatives.

\section{Forest Carbon Partnership Facility (FCPF)}

The World Bank's Forest Carbon Partnership Facility (FCPF) under its Strategic Environmental and Social Assessment (SESA) has developed a set of safeguards. A set of ten policies of SESA allows for the incorporation of environmental and social concerns into the formation of national REDD+ strategies and ensures that the FCPF readiness activities comply with the World Bank's policies during the strategic planning phase of REDD+ projects and programmes, considering that these strategic activities could have potentially farreaching impacts. For REDD+, the most relevant World Bank policies are likely to be on Environmental Assessment (OP/BP 4.01), Natural Habitats (OP/BP 4.04), Forests (OP/ $\mathrm{BP}$ 4.36), Involuntary Resettlement (OP/BP 4.12) and Indigenous Peoples (OP/BP 4.10) (FCPF 2011).

A specific output of SESA is the Environmental and Social Management Framework (ESMF). The ESMF is a framework to avoid and/or mitigate and manage potential risks of the REDD+ strategy options related to adoption of future REDD+ projects, activities and policies. The strength of SESA for REDD+ is that it combines analytical and participatory approaches by engaging with a number of key stakeholders. It follows an iterative process throughout the REDD+ readiness phase, including the development of national Readiness Plan Proposal (R-PP). Furthermore, SESA advocates integration of key environmental and social considerations relevant to REDD+ at the earliest stage of decision making and establishing their interlinkages with economic, political and 
institutional factors. Through this process, social and environmental opportunities and desirable outcomes are identified and agreed upon to ensure that the REDD+ programme will be sustainable and contribute to the country's development objectives.

\section{UN-REDD Programme}

The UN-REDD Programme has drafted a set of six principles and 18 criteria and associated tools and guidance (UN-REDD 2012) to develop the Social and Environmental Principles Framework for REDD+. Six key principles are democratic governance, stakeholders' livelihoods, policy coherence, protection and conservation of natural forests, maintenance and enhancing of multiple functions of forests, and minimizing indirect adverse impacts on ecosystem services and biodiversity. This framework follows an approach of 'do no harm' and aims to ensure that UN obligations and commitments are met in the REDD+ programme, including United Nations Declaration on Rights of Indigenous Peoples (UNDRIP), FPIC and UN Development Group Guidelines on Indigenous People.

The Framework has two main components:

i ) Aminimum standard risk assessment and mitigation - The UN-REDD Programme funded programmes/projects/actors will have to comply with a set of minimum environmental and social standards. These principles frame a code of conduct for activities supported by the UN-REDD Programme and are based on international treaties, conventions and best practice guidance.

ii) An assessment of impact magnitude - It is intended to minimize social and environmental risks and maximize multiple benefits for climate, sustainable development and conservation.
To complement this, the UN-REDD Programme has also developed guidance and activities on a participatory governance assessment and monitoring tools for REDD+ to identify governance challenges and recommend responses (UN-REDD 2012). Additionally, it has also developed guidelines on stakeholder engagement and FPIC and the provision of information on REDD+ governance. Furthermore, 'benefits and risk tool' is also being developed to help apply and elaborate the concepts encompassed in the social and environmental principles and criteria.

\section{REDD+ Social and Environmental Standards}

The REDD+ Social and Environmental Standards (REDD+ SES) is a multi-stakeholder initiative facilitated by the Climate, Community and Biodiversity Alliance (CCBA) and CARE International (REDD+ SES 2012). They have been developed to support the design and implementation of government-led REDD+ programmes that respect the rights of indigenous peoples and local communities and generate significant social and environmental benefits. The standards have been explicitly designed to go beyond laying out minimum safeguards and to identify and elaborate benefits. The REDD+ SES consists of principles, criteria and indicators and a process of monitoring, reporting and verification (MRV) through multi-stakeholder assessments. A set of seven principles, listed below, provides the key objectives that define high social and environmental performance of a REDD+ programme.

1. Respect for rights of indigenous peoples and local communities, including FPIC

2. Equitable benefit sharing

3. Benefits for indigenous peoples and local communities improve human well-being 
4. Contribution to broader sustainable development

5. Maintenance of biodiversity and ecosystem services

6. Full and effective participation and access to information

7. Compliance with national and international laws

At principle and criteria level, the standards are intended to be generic (i.e. the same across all countries). At indicator level, there is a multistakeholder process for country-specific interpretation to develop a set of indicators that are tailored to the context of a particular country. The standards have been piloted in countries including, Ecuador, Nepal, Tanzania, the State of Acre in Brazil and the Province of Central Kalimantan in Indonesia.

\section{Rainforest Alliance Social and Environmental Safeguards for REDD+}

Rainforest Alliance Social and Environmental Safeguards for REDD+ were developed in Brazil through an inclusive process. It includes eight principles and 27 criteria (Bonfante et al. 2010). The principles address legal compliance, rights recognition and guarantee; benefit sharing; economic sustainability; improvement in quality of life and poverty alleviation; environmental conservation and recovery; participation of all stakeholders; monitoring and transparency; and governance.

\section{Sustainable Forest Management Principles and Criteria}

The principles and criteria for sustainable forest management (SFM) put forward by the Forest Stewardship Council (FSC), which are based on ten principles (summarized below) (FSC 2012), can also be useful to shape safeguards for REDD+.
- Compliance with laws and FSC Principles - to comply with all laws, regulations, treaties, conventions and agreements, together with all FSC Principles and Criteria.

- Tenure and use rights and responsibilities - to define, document and legally establish long-term tenure and use rights.

- Indigenous peoples' rights - to identify and uphold indigenous peoples' rights of ownership and use of land and resources.

- Community relations and worker's rights - to maintain or enhance forest workers' and local communities' social and economic well-being.

- Benefits from the forest - to maintain or enhance long-term economic, social and environmental benefits from the forest.

- Environmental impact - to maintain or restore the ecosystem, its biodiversity, resources and landscapes.

- Management plan - to have a management plan implemented, monitored and documented.

- Monitoring and assessment - to demonstrate progress towards management objectives.

- Maintenance of high conservation value forests - to maintain or enhance the attributes which define such forests.

- Plantations - to plan and manage plantations in accordance with FSC principles and criteria.

\section{Women's Carbon Standard}

In April 2013, Women Organizing Change in Agriculture and Natural Resource Management (WOCAN) launched Women's Carbon Standard (WCS). The WCS is a set of project 
design guides that complement existing compliance or voluntary carbon standards, such as the Verified Carbon Standard, the Gold Standard and the Clean Development Mechanism (CDM), among others. The WCS specifically includes guidance as how to encourage and then measure women's empowerment and participation in carbon projects (WOCAN 2013). The WCS specifically includes mechanisms that measure women's empowerment and participation in carbon or ecosystem services projects. The WCS will quantify beneficial outcomes for women, their families and communities. As proposed by WOCAN, the WCS espouses three principles:

1. WOCAN will challenge the prevailing public perception of women as members of vulnerable groups most affected by climate change, thus limiting their opportunities to participate in the market. This will be done by showcasing their roles as entrepreneurs, resource managers and leaders who engage with carbon markets.

2. WOCAN will employ the WCS as a transparent, rigorous and realistic mechanism that can promote women's empowerment using private sector market approaches. This is necessary to quantify and value women's contributions to green house gas (GHG) mitigation.

3. The WCS will permit projects that include social co-benefits for women to receive a premium price on the carbon market. Corporate Social Responsibility (CSR) buyers - those companies who pay for offsets to enhance their brand image-are willing to pay more for credits that are generated from projects that have compelling human interest stories.

\section{Other Initiatives}

The need for safeguards is also being reflected in a number of other initiatives, including bilateral agreements. For example, the
Government of Norway's International Forests and Climate Initiative has made their funding to Guyana and Indonesia conditional upon implementation of certain governance requirements aimed at limiting deforestation. Similarly, other projects, such as those funded by Australia and others, include frameworks specifically targeting gender equity and environmental assessment. The Clean Development Mechanism (CDM) provides safeguards for stakeholders, including that they must be consulted during the planning of a CDM project activity and that designated operational entities must verify that local stakeholders' concerns have been considered and properly addressed by project developers. Also, project participants are able to communicate with the Executive Board directly on matters related to a project, its registration and the issuance of certified credits.

\section{EMERGING CONCERNS ON THE IMPLEMENTATION OF SAFEGUARDS}

The implementation and monitoring of safeguards have been a contentious issue in the REDD+ debate. Following the Cancun Agreement on REDD+ safeguards, major decisions on how the scheme will be funded and how both 'safeguards' and deforestation will be monitored remain unresolved (Austin et al. 2010). Some argue that safeguards could potentially make implementation of REDD+ more complex and increase transaction costs (Jagger et al. 2012), and therefore, less able to compete with other land uses or with other sources of carbon credits. One simple example of this is related with capacity building at grass roots level, as experienced in the grass roots project being implemented by RECOFTC in four countries. The project has delivered training programmes on FPIC and gender mainstreaming, and simplification of the international language on climate change, REDD+ and safeguards to the level that local 
stakeholders can understand and communicate back their concerns to the policymakers involves significant efforts and costs. On the other hand, a number of civil society organizations and community representatives argue that the safeguards do not go far enough to protect the culture and livelihood of forest-dependent communities. And it will be important that the development and implementation of safeguards takes the points of view of these REDD+ stakeholders into account.

Following are some of the major concerns and challenges regarding formulation and implementation of social safeguards at national level.

\section{Customizing and Harmonizing Safeguards}

One of the key challenges at national level is with regard to customizing the internationally developed safeguards mechanism and integrating them into the national processes. This requires institutional frameworks that can establish national interpretations of global standards of safeguards. Integrating the development of safeguards within country systems is important in allowing the flexibility to define safeguards based on national issues or existing national safeguards systems. For example, a number of countries already have welldefined policies on gender mainstreaming in the forestry sector in general, which can be easily adapted and contextualized to inform the relevant processes at national level with regard to REDD+ safeguards. Such a process will help in maintaining sovereignty of the process while ensuring that national interpretation responds effectively to international common principles.

The existing international initiatives related to the development of REDD+ safeguards demonstrate the commonality and overlap in their approaches, yet there are differences in the levels of details of the requirements and the intended processes and outcomes of application, evaluation, and monitoring of the safeguards. All the principles, criteria and indicators, as developed by different agencies are important references. However, they need to be harmonized with the national circumstances, as national governments are expected to promote and support REDD+ safeguards in their own situations. This is more challenging for those countries which are involved in both the UN-REDD Programme and the World Bank's FCPF programme.

\section{Civil Society and Community Concerns}

Meaningful and genuine engagement of the stakeholders concerned is necessary while drafting national-level REDD+ safeguards and integrating them into national REDD+ processes. Especially indigenous peoples and local communities, including women and marginalized groups, need to be informed and engaged. They may need to be supported by technical experts, resources and capacitybuilding services to enable them to participate meaningfully and effectively. Additionally, the elements of good governance, empowerment of women, benefit sharing and long-term livelihood security of indigenous peoples and local communities need attention, particularly for ensuring social safeguards of REDD+.

Experiences from the ongoing grass roots project of RECOFTC have reflected that indigenous peoples and local communities have genuine concerns related to REDD+ and uncertainty in various aspects of resource governance caused by it. These are basically linked with the nonrecognition of the land tenure rights over the forest land and resources, elite capture of resources and weak capacity of local communities and marginalized groups to raise their concerns with policymakers, leaving them vulnerable to exploitation. The complex language and the related concepts associated with REDD+ and relevant safeguards are other 
dimensions to this challenge, which in many instances act as a barrier to the meaningful and effective participation of these communities in REDD+ planning and implementation.

\section{Land Rights and Benefit Sharing}

Unclear rights of forest-dependent communities, including indigenous peoples and local communities, to land, territories and resources are other major challenges to formulating safeguards. Government agencies often have ambiguous, unclear and sometimes conflicting mandates regarding the management of land resources, which can cause problems with defining and negotiating rights issues in both setting standards for social safeguards and their implementation. Besides clarity on property rights over carbon, issues related to land tenure and other user rights, transparency, accountability and broad participation of local communities, indigenous peoples and the private sector should underlie the achievements of multiple social and environmental benefits of REDD+. Linked to this is the issue of equitable benefit-sharing and going beyond 'no harm' to 'more good'. Since forests are more than carbon, they provide benefits through diverse ecosystem services, including water and biodiversity.

\section{Enforcing Safeguards}

Once the safeguards are drafted, implementing them on the ground is equally challenging. If implemented too rigidly, they may create conflict over use of forest resources and the resultant benefits from them between and among stakeholders. This could, in turn, affect the acceptance as well as growth of REDD+ severely and may limit its advantages to limited forestlands. The need is to ensure that these safeguards are enforced wisely, not dogmatically, which while appearing virtuous, may harm the very people that are sought to be protected. Another important aspect that will need adequate consideration while implementing the safeguards is the approach of REDD+ implementation. The process of REDD+ implementation at national level involves a phased approach, therefore, demanding for a flexible approach in integrating and adapting them to and in all stages of REDD+. Learning from other similar initiatives such as the European Union (EU) Forest Law Enforcement, Governance and Trade Initiative (FLEGT), FSC principle about SFM, which are focused on combating illegal logging and trade in illegal timber, can help in complementing the process of design and implementation of REDD+ safeguards at national level.

All these initiatives will need strong coordination between and among different line agencies at national and sub-national levels, with adequate capacity development support, and stronger governance structure at local level. For effective implementation of FPIC, an easily accessible grievance mechanism will need to be in place to provide an opportunity to marginalized communities to voice their concerns and also to address the challenge of elite capture.

\section{Monitoring of Safeguards}

Discussions on MRV have so far tended to focus on the technical elements of REDD+ implementation, primarily carbon measurement. However, it is equally important to build monitoring frameworks and capacity for MRV for social safeguards, including governance system of REDD+ implementation, at national and local level.

After the Cancun Agreement, parties to the convention are currently in the process of developing guidance to create a system for providing information on how the REDD+ safeguards are being addressed and respected. The UN-REDD programme has drafted social principles and a risk identification and mitigation tool to be used in the UN-REDD national programme for monitoring REDD+ 
governance, an important element of the social safeguards. The particular focus of this process is on defining key aspects of governance relevant to REDD+ and how these could be monitored, including core governance parameters, such as clearly identified roles and responsibilities of different institutions, coordination among them and across sectors, participation of stakeholders, transparency of decision making and developing principles for effective monitoring. By supporting a mechanism for monitoring and reporting on how safeguards are addressed and how social and environmental benefits of REDD+ programmes have been delivered, CCBA and CARE International are piloting a new approach to social and environmental safeguards monitoring in selected countries.

Another initiative for MRV on safeguards has been from Global Witness, which has developed a set of principles advocating independent monitoring of REDD+ safeguards by a third party that is endorsed by the state authorities. Such an independent assessment is to look into compliance and observation of and guidance on official law enforcement systems. Furthermore, the role of civil society is important in independent monitoring, which could help in improving transparency and accountability by publicly reporting on the evidence gathered in an objective and unbiased manner. Transparency in information sharing between and among lead ministries and agencies is necessary to integrate the social and environmental considerations and recommendations into policy formulation processes and developing independent monitoring of REDD+ safeguards.

\section{CONCLUSION}

The recent initiatives of formulating social and environmental safeguards for REDD+ implementation by multilateral and bilateral agencies have provided a solid basis for formulating them at national level.
Nevertheless, there is a need to customize and harmonize the safeguard measures. In this process, there are a number of challenges which need adequate attention from the national governments and other stakeholders. Moreover, it is equally important to create appropriate and measurable indicators which are also culturally sensitive in order to monitor the implementation of the social safeguards. While nationalizing REDD+ safeguards, looking beyond carbon benefits and exploring opportunities for additional economic incentives and maximizing the co-benefits will help improve buy-in from indigenous peoples and local communities for the REDD+ programme. Transparency and participation lie at the heart of social safeguards. Indigenous peoples and local communities need stronger capacity to actively participate in REDD+, particularly in the development of social standards. Raising stakeholder awareness of participatory approaches is essential and requires substantial capacity-building efforts, followed by support at local to national level. All these initiatives at national and sub-national level will only work when coordination among key stakeholders within and outside the government is guaranteed.

\section{REFERENCES}

Austin, K., Daviet, F. and Stolle, F. 2010. The REDD+ Decision in Cancun. Washington, D.C.: World Resources Institute.

Bonfante, T.M., Voivodic, M. and Filho, L.M. 2010 Developing Social and Environmental Safeguards for REDD+: A Guide for Bottom-up Approach. Imaflora.

FCPF. 2011. Forest Carbon Partnership Facility (FCPF) Readiness Fund: Common Approach to Environmental and Social Safeguards for Multiple Delivery Partners. Washington, DC.: The World Bank.

FSC. 2012. Forest Steward Council Principles and Criteria for Forest Stewardship. (https://ic.fsc.org/principles-andcriteria.34.htm accessed on 25 July 2013)

Jagger, P., Lawlor, K., Brockhaus, M., Gebara, M.F., Sonwa, D.J. and Resosudarmo, I.A.P. 2012. REDD+ Safeguards in National Policy Discourse and Pilot Projects. In: A. Angelsen, M. Brockhaus, W.D. Sunderlin and L.V. Verchot (Eds.), Analysing REDD+: Challenges and Choices. CIFOR, Bogor, Indonesia. 
Kant, P., Chaliha, S. and Wu. S. 2011. REDD Safeguards of Cancun. IGREC Working Paper IGREC 19: 2011. New Delhi: Institute of Green Economy.

Murphy, D. 2011. Safeguards and Multiple Benefits in REDD+ Mechanism. International Institute for Sustainable Development and Partnership for the Tropical Forest Margins. (http://www.iisd.org/pdf/2011/redd_safeguards. pdf accessed on 25 July 2013)

RECOFTC. 2011. Grassroots Capacity Building for REDD+ in the Asia-Pacific. Annual Progress Report Submitted to NORAD, September 2011. Bangkok: The Center for People and Forests.

RECOFTC. 2012. Grassroots Capacity Building for REDD+ in the Asia-Pacific. Annual Progress Report Submitted to NORAD, September 2012.Bangkok: The Center for People and Forests.

REDD+ SES. 2012. REDD+ Social and Environmental Standards. (http://www.redd-standards.org/files/
REDDSES Version 2/REDDSES Version 2 10_September_2012.pdf accessed on 26 July 2013).

UNFCCC. 2009. Copenhagen Accord. United Nations Framework Convention on Climate Change. (http:// unfccc.int/resource/docs/2009/cop15/eng/107.pdf accessed on 23 July 2013).

UNFCCC. 2011. The Cancun Agreements: Outcome of the work on the Ad Hoc Working Group on Long-Term Cooperative Action under the Convention. Report of the Conference of the Parties on its Sixteenth Session, held in Cancun from November 29-December 10, 2010. FCCC/CP/2010/7/ Add.1.

UN-REDD. 2012. UN REDD Programme Social and Environmental Principles and Criteria. (http://www.unredd.org/Multiple Benefits SEPC/tabid/54130/ Default.aspx accessed on 23 July 2013).

WOCAN. 2013. Women's Carbon Standard: Program Guide, Version April 2013. (http://www.womenscarbon.org/sites/ default/files/womens-carbon-standard-program-guide.pdf accessed on July 22 2013). 